\title{
A transformação dos fatos em discurso: um olhar argumentativo
}

\author{
La transformation des faits en discours: un regard argumentatif
}

Cristiane Dall Cortivo Lebler ${ }^{1}$

Universidade de Santa Cruz do Sul - Santa Cruz do Sul - Rio Grande do Sul - Brasil

\begin{abstract}
Resumo: Este artigo realiza um estudo polifônico e argumentativo de dois discursos publicados em dois portais online de notícias. Nosso objetivo é discutir o modo como os locutores constroem sentidos distintos em cada um dos textos a partir do mesmo fato: a divulgação, pela Organização das Nações Unidas, do relatório contendo os dados do Índice de Desenvolvimento Humano. Para embasar este estudo, buscamos o referencial teórico da Teoria da Argumentação na Língua em sua fase atual, a Teoria dos Blocos Semânticos, desenvolvida por Marion Carel e Oswald Ducrot. Nossa hipótese é de que a subjetividade é responsável pela construção de pontos de vista diferentes a respeito da mesma realidade.
\end{abstract}

Palavras-chave: Notícia; Argumentação; Subjetividade; Polifonia

Résumé: Cet article réalise un étude polyphonique et argumentatif de deux discours publiés en deux portails de nouvelles. Notre objectif est de discuter le moyen comment les locuteurs construisent sens différents dans chaque texte à partir du même fait: la divulgation du rapport, par L'Organisation des Nations Unies, avec les données de l'Indice de Développement Humain. Pour appuyer cet étude, nous avons pris le réfèrent théorique de la Théorie de L'Argumentation dans la Langue, dans son phase actuelle, la Théorie des Blocs Sémantiques, développée par Marion Carel et par Oswald Ducrot. Notre hypothèse c'est que la subjectivité est la responsable pour la construction des différents points de vue à propos de la même réalité.

Mots-Clés: Nouvelle; Argumentation; Subjectivité;. Polyphonie

\section{Introdução}

O estudo da linguagem, especialmente quando centrado em seu uso efetivo, transforma o modo como os indivíduos percebem - e recebem - os discursos em seu dia a dia. Não é raro, ao lermos uma notícia ou ao ouvirmos um discurso qualquer na televisão, flagrar-nos analisando os sentidos implícitos construídos por esses discursos e os recursos linguísticos utilizados para se chegar a esses sentidos.

Tal perspicácia na compreensão dos discursos leva os indivíduos a realizarem leituras mais críticas e menos ingênuas acerca da realidade. Isso significa que se tornaram capazes de perceber que, por trás dos discursos de que são alvo, sempre existem pontos de vista que são defendidos, muitas vezes de modo indireto. É o que acontece, com certa frequência, nos meios de comunicação jornalísticos.

Há aproximadamente um ano, quando da divulgação pela Organização das Nações Unidas (ONU) dos dados do Índice de Desenvolvimento Humano (IDH), duas notícias sobre o mesmo tema chamaram a atenção: uma delas foi publicada no portal de notícias $G 1$; a outra foi publicada no portal online da revista Carta Capital. Ambas comentavam o mesmo fato: os resultados do IDH e a posição do Brasil no ranking da ONU. Os pontos de vista defendidos em cada uma das notícias, entretanto, eram totalmente opostos.

É do exame de cada uma dessas notícias que trata este artigo. Nosso objetivo é analisar e descrever o modo como os discursos foram construídos, evidenciando o posicionamento de cada um dos locutores a respeito do

\footnotetext{
${ }^{1}$ Doutora em Letras pela PUCRS. Professora colabora do Programa de Pós-Graduação em Letras - Mestrado em Leitura e Cognição - da Universidade de Santa Cruz do Sul. E-mail: cristianedc@unisc.br
} 
tema e os recursos linguísticos utilizados em cada um dos textos para levar a cabo a defesa da argumentação. Para alcançar tal objetivo, ancoramos nosso trabalho nos pressupostos da Teoria da Argumentação na Língua, desenvolvida hoje por Oswald Ducrot e por Marion Carel, cuja fase atual denomina-se Teoria dos Blocos Semânticos.

Inicialmente, faremos um percurso teórico evidenciando os conceitos que serão imprescindíveis para a análise, dentre eles a noção de subjetividade, que consideramos essencial para explicarmos o fato de os discursos construírem realidades distintas. Após, procederemos à análise de cada um dos discursos em evidência e, por fim, comentaremos os resultados a título de considerações finais.

\section{A linguagem, a subjetividade e a atividade discursiva}

Em se tratando de o objetivo deste trabalho ser a análise de duas notícias acerca do mesmo tema, consideramos oportuno trazer a discussão a respeito do conceito de subjetividade que, segundo nosso ponto de vista, explica a possibilidade de construirmos discursos distintos a respeito do mesmo fato. Essa subjetividade, responsável pelo modo como o locutor constrói seu ponto de vista, materializa-se no discurso especialmente pelo fato de este ser responsável pela construção da realidade através da linguagem.

Abordar a linguagem como o terreno da subjetividade (e da intersubjetividade, se se aceita o pressuposto de que há, na língua, não apenas um $e u$, mas também um $t u$ a quem o locutor $e u$ se dirige) não é algo propriamente novo. Ducrot (1990a), em um texto denominado Linguística $Y$ Verdad, apresenta um percurso segundo o qual o modo de conceber o significado da língua como algo referente à realidade foi substituído e contestado, de diversos modos e por diferentes teóricos, ao longo da história das investigações linguísticas.

Tal concepção, denominada também "concepção veritativa" ou "logicóide", afirma que as palavras da língua não têm sentido, uma vez que parte do princípio de que a função principal da língua é descrever a realidade, reproduzindo dela uma imagem fiel. O sentido, dessa forma, não estaria contido nas palavras - ou não seria construído por elas - mas estaria ancorado à realidade que a língua representa e da qual transmite um valor de natureza informacional, passível de julgamentos em termos de verdade e falsidade.

Tal concepção foi criticada de modo parcial pela gramática de Port Royal e pela Teoria da Enunciação de Charles Bally (DUCROT, 1990a). Essas visões acerca da linguagem estão assentadas sobre os pressupostos cartesianos do pensamento, segundo os quais há uma distinção entre as instâncias do entendimento e da vontade. Entendimento e vontade aparecem marcados no enunciado, segundo a teoria enunciativa de Bally, através dos elementos modus e dictum: o primeiro corresponde à atitude da vontade, enquanto o segundo corresponde às representações do entendimento. Segundo Ducrot (1990a), modus e dictum, embora representem a distinção entre dois componentes do enunciado, não o fazem de modo satisfatório, uma vez que ambos são representações de natureza informativa: o primeiro diz respeito a uma representação de um objeto interior, enquanto o segundo trataria da representação de um objeto exterior.

No campo da Pragmática, a distinção entre as representações do modus e do dictum, realizadas por Bally, aparece na Teoria dos Atos de Fala de Searle sob as denominações força ilocucionária e conteúdo proposicional. Trata-se de dois elementos amalgamados no enunciado, um de natureza subjetiva e outro de natureza objetiva. As forças ilocucionária (de ordem, de afirmação, de pergunta, por exemplo), pelo fato de serem autorreferenciais, ou seja, pelo fato de fazerem alusão a si mesmas e não a elementos extralinguísticos, escapam de todo e qualquer julgamento em termos de verdade ou falsidade. Searle, entretanto, semelhante às "condições de verdade" da concepção veritativa da linguagem, incorpora em sua teoria as "condições de felicidade", segundo as quais existe um conjunto de fatores que deve ser atendido para que o ato de fala, correspondente à determinada força ilocucionária, se cumpra. Tal substituição consiste, sob a ótica de Ducrot (1990a), num retrocesso à própria descoberta realizada pelos filósofos da linguagem, já que abandonaram o aspecto considerado como o mais original de sua teoria.

Não mais relacionado aos estudos da Pragmática, mas à Teoria da Enunciação de Benveniste, o conceito de subjetividade ganha, então, lugar de destaque nos estudos da linguagem. Afirma o autor: "a 'subjetividade' de que tratamos aqui é a capacidade do locutor para se propor como "sujeito"” (BENVENISTE, 2005, p. 286) (grifos do autor). Tal definição faz referência ao fato de o locutor transformar-se em sujeito por um processo que o teórico denomina de apropriação, e que está fortemente ligado ao conceito de enunciação definido por Benveniste. Enunciação, para o teórico, consiste em "colocar a língua em funcionamento através de um ato individual de utilização" (BENVENISTE, 1989, p. 82).

A subjetividade benvenistiana se define através da concretude linguística, uma vez que a transformação do locutor em sujeito pressupõe a enunciação, que acontece por meio de índices específicos, aos quais o autor denomina "aparelho formal da enunciação". Os índices específicos responsáveis pela subjetividade são intrínsecos à noção 
de pessoa, ou seja, eu e tu. Subjetividade, portanto, é um conceito que, ligado à categoria de pessoa, não pode estar apartado da noção de intersubjetividade, já que a noção de pessoa compreende o papel do locutor e o papel do interlocutor. Além disso, subjetividade e intersubjetividade se encontram amalgamadas no fato de Benveniste considerar a linguagem como constitutiva do homem:

Não atingimos nunca o homem separado da linguagem e não o vemos nunca inventando-a (sic.). Não atingimos jamais o homem reduzido a si mesmo e procurando conceber a existência do outro. É um homem que encontramos no mundo, um homem falando com outro homem, e a linguagem ensina a própria definição de homem. (BENVENISTE, 2005, p. 285).

Já na Teoria da Argumentação na Língua, a subjetividade aparece ligada à intersubjetividade naquilo que o Ducrot (1990b) denomina valor argumentativo. $\mathrm{O}$ autor opõe-se à concepção tradicional de sentido, que afirma que à língua pertencem três indicações: uma de natureza objetiva, uma de natureza subjetiva e, por fim, outra de natureza intersubjetiva. A oposição do autor à concepção tradicional de sentido dá-se, especialmente, com relação às indicações objetivas, uma vez que a língua não comporta um componente objetivo, que reproduziria fielmente a realidade, dela fornecendo uma descrição. Antes disso, à língua pertencem apenas as indicações subjetivas, que dizem respeito às atitudes do locutor frente à realidade, e as indicações intersubjetivas, que dizem respeito a uma espécie de "chamado" que o locutor faz àquele a quem dirige seu discurso. Ainda que nossos discursos constituam "descrições" de pessoas, fatos ou da realidade, de modo geral essas descrições estão impregnadas pelo componente subjetivo, ou seja, pelo modo bastante particular como o locutor percebe essa realidade.

Ao desconsiderar o componente objetivo como constitutivo do sentido e ao integrar à descrição semântica da língua apenas os componentes subjetivo e intersubjetivo, Ducrot (1990b) cria o conceito de valor argumentativo, que encapsula a subjetividade e a intersubjetividade. O valor argumentativo é definido como a orientação argumentativa que determinada palavra dá ao discurso, o que impede que certas continuações lhes sejam concatenadas, autorizando outras. A ideia de que as palavras determinam as possibilidades de continuação que lhe podem ser acrescentadas é fundamental para compreendermos a construção dos sentidos que analisaremos, uma vez que alguns termos empregados pelos locutores têm papel capital na construção da argumentação, já que orientam o leitor para a construção do sentido.

\section{Sobre a origem da subjetividade na Argumentação na Língua}

A subjetividade em Ducrot, segundo a construímos nestas linhas, encontra respaldo nos fundamentos teóricos em que se assentam as hipóteses internas da ANL, ou seja, nos conceitos construídos para dar conta das explicações acerca da linguagem. Tais fundamentos teóricos remetem a dois elementos: em primeiro lugar, ao conceito saussuriano de valor, que determina de maneira decisiva o modo como o sentido da língua é percebido, descrito e explicado; em segundo lugar, a enunciação, definida como a transformação da língua em discurso por um locutor, que contribui para a construção do conceito de subjetividade, o qual acreditamos ser importante para explicar os discursos que ora analisaremos.

A incorporação aos pressupostos da ANL da noção saussuriana de valor e da enunciação é fundamental para a concepção de linguagem construída pela Teoria, cuja fundamentação encontra-se no fato de a atividade linguística produzir sempre uma imagem de si mesma. Essa auto-referencialidade da atividade linguística tem duas faces: a face propriamente linguística, marcada na sua materialidade, e a face enunciativa, marcada no enunciado através de figuras cujo aparecimento está ligado ao uso da língua. São o locutor e os enunciadores que instauram no discurso um sentido de natureza polifônica.

Iniciemos pela abordagem do auto-referencialismo a partir do conceito de valor. A noção de valor, para Saussure (2006), implica que o significado de um signo somente poderá ser definido se levadas em consideração as relações que este signo mantém com os demais signos da língua. Tais relações entre signos são, portanto, de natureza linguística, o que restringe o significado das palavras ao domínio da língua, sem que a ele se vincule qualquer indicação informativa ou relativa à realidade. A noção de valor fundamenta alguns conceitos da ANL, dentre os quais destacamos o valor argumentativo, que nada mais é do que as combinações entre os signos. É dessa abordagem que nasce o slogan, frequentemente utilizado pelos teóricos da ANL, a argumentação está na língua.

Tal slogan encontra suporte na afirmação de que a realidade nada mais é do que um tema para debate entre dois indivíduos, visto que todo enunciado é fruto da percepção singular de um locutor acerca daquilo de que fala, ou seja, da discursivização dos fatos que realiza em seus enunciados. Essa percepção singular realizada por um locutor não diz respeito a sentimentos ou a impressões psicológicas, mas unicamente ao sentido que é construído pela língua por meio da enunciação. É aqui que se encontra marcada a segunda face constitutiva da subjetividade, a face enunciativa. 
Se admitimos que o sentido é subjetivo e que essa subjetividade advém de uma concepção de linguagem que exclui fatores extralinguísticos, é preciso considerar que somente a língua em uso é capaz de construir sentido e expressar subjetividade: locutor e enunciação são dois aspectos que, embora previstos pela língua, não aparecem senão naquilo que Saussure denomina fala, ou seja, no uso da língua, em seus usos individuais e momentâneos.

Para Ducrot (1987), o sentido do enunciado é caracterizado também como uma representação da sua enunciação, uma vez que carrega consigo determinadas marcas que são exclusivas da atividade linguística, as marcas da polifonia. O estudo polifônico do sentido deve levar em conta os usos reais das frases, nos quais há a confrontação das frases com os seus respectivos enunciados, já que é a esta última instância que pertencem os enunciadores, os locutores e as suas atitudes, cujo surgimento está restrito à transformação da língua em discurso (CAREL, DUCROT, 2008, p. 18).

\section{Alguns conceitos para a análise}

Para procedermos à análise dos discursos, é necessário que sejam apresentadas algumas ferramentas que nos serão úteis para demonstrar o modo como cada uma das notícias constrói o sentido de modo singular. De um lado, são os conceitos de encadeamento argumentativo, bloco semântico e argumentação interna e externa ao léxico. De outro, são os conceitos referentes à Teoria Polifônica da Enunciação.

\subsection{Teoria dos Blocos Semânticos}

Partindo da ideia de que o sentido na língua advém da relação entre os signos, Carel e Ducrot (2008) definem que aos enunciados subjazem os encadeamentos argumentativos, também denominados pelos autores de argumentações. Uma argumentação é descrita como a sequência de duas frases articuladas por um conector, sendo a primeira denominada suporte e a segunda, aporte. As argumentações podem ser normativas se a relação entre as frases for expressa por um conector do tipo portanto (Pedro gosta de cães, portanto adotou um filhote); já as argumentações serão transgressivas se a relação entre as frases for expressa por conectores do tipo no entanto (Pedro gosta de cães, no entanto não adotou um filhote).

Da relação entre os dois segmentos (frases) que compõem as argumentações resulta um sentido que Ducrot (2005a) denomina bloco semântico. O bloco semântico nasce da interdependência entre suporte e aporte e pode ser expresso de quatro formas diferentes, nas quais há a combinação do suporte e do aporte com a negação e os conectores $D C^{2}$ e $P T^{3}$. Cada uma dessas quatro formas de expressar o sentido do bloco semântico é denominada aspecto argumentativo, que se relaciona com as demais de três formas distintas: podem ser recíprocos, transpostos ou conversos uns em relação aos outros. Os exemplos abaixo elucidam a teorização que apresentamos.

(E1) - Pedro gosta de cães, portanto adotou um filhote. Aspecto argumentativo 1 - gostar de cães DC adotar um filhote

(E2) - Pedro gosta de cães, no entanto não adotou um filhote.

Aspecto argumentativo 2 - gostar de cães PT neg adotar um filhote

(E3) - Pedro não gosta de cães, portanto não adotou um filhote

Aspecto argumentativo 3 - neg gostar de cães DC neg adotar um filhote

(E4) - Pedro não gosta de cães PT adotou um filhote.

Aspecto argumentativo 4 - neg gostar de cães PT adotar um filhote

$\mathrm{O}$ aspecto argumentativo 1 é recíproco ao aspecto argumentativo 3, converso ao aspecto argumentativo 2 e transposto ao aspecto argumentativo 4. Já o aspecto argumentativo 2 é recíproco em relação ao aspecto 4, converso ao aspecto argumentativo 1 e transposto ao aspecto argumentativo $3 .^{4}$ Todos esses aspectos argumentativos compreendem modos particulares de expressar o sentido do bloco semântico. As relações entre os aspectos argumentativos são constitutivas umas das outras e a polifonia aparece na evocação desses aspectos argumentativos enquanto pontos de vista cuja origem está ligada aos enunciadores.

Ainda segundo a concepção da ANL, o sentido das palavras está constituído por discursos - argumentações - que a elas podem estar associados de dois modos: internamente e externamente. Um discurso está associado a uma palavra de maneira interna quando a argumentação constitui uma espécie de paráfrase da palavra. Citamos como exemplo o enunciado Joana é competente, em que à palavra competente pode ser associado internamente o aspecto argumentativo realiza as tarefas com eficiência $D C$ é capaz, no qual a palavra em análise não participa da construção do aspecto. Já a associação de um discurso a uma palavra se dá de modo externo quando esta participa como um dos segmentos da argumentação. Tomando ainda como exemplo o enunciado Joana é competente,

\footnotetext{
A sigla DC é a abreviação do conector prototípico portanto.

A sigla PT é a abreviação do conector prototípico no entanto.

4 Para estudo mais aprofundado das relações entre os aspectos argumentativos constitutivos do bloco semântico sugerimos a leitura de Ducrot (2005b).
} 
a argumentação externa que pode ser associada à palavra competente traduz-se pelo aspecto argumentativo competente DC eficiente.

\subsection{Teoria polifônica da Enunciação}

A Teoria Polifônica da Enunciação tem como proposta principal a oposição à ideia de unicidade do sujeito falante. Isso significa que, segundo essa abordagem, não há apenas um personagem por trás de um enunciado, mas sim há um desdobramento do sujeito falante em três figuras, cujos papéis são bastante variados. O termo polifonia, já atrelado à música e aos estudos de literatura desenvolvidos por Bakhtin, ganha um contorno especial na proposta realizada por Ducrot $(1987,1990$ c) e Carel e Ducrot (2008), cujo estudo concentra-se na análise dos enunciados relativamente ao seu aspecto linguístico.

Para Ducrot (1990c), um autor de um enunciado nunca se expressa diretamente, mas põe em cena uma gama de personagens que denomina enunciadores. São os pontos de vista desses enunciadores, com os quais o locutor mantém relações e toma determinadas atitudes, que são constitutivos do sentido dos enunciados. Isso significa que o sentido, além de ser de natureza linguística, também contém traços semânticos ligados à enunciação, ou seja, à transformação da língua em discurso por um locutor.

A teoria da polifonia se estrutura em torno de alguns conceitos: trata-se das funções de locutor, sujeito empírico e enunciador; das atitudes - concordar, assumir ou opor-se; e da assimilação. Cada um desses grupos de conceitos compõe uma face do sentido do enunciado, já que este está constituído por um certo número de pontos de vista, pela atitude que o locutor toma em relação aos enunciadores e pela assimilação que faz de um locutor a uma pessoa X. Vejamos cada um desses conceitos e como compõem o sentido dos enunciados.

O locutor é definido por Carel e Ducrot (2008) como o ser a quem se atribui a responsabilidade pelo enunciado e está identificado pelas marcas de primeira pessoa. Portanto, todo discurso que ouvimos - ou lemos - tem como responsável um ser de linguagem que pode ser, frequentemente, distinto do sujeito empírico, este responsável pelos movimentos articulatórios e psicofisiológicos da enunciação. Já o enunciador é definido como a origem dos pontos de vista, são seres discursivos que surgem na e com a enunciação. Os enunciadores são colocados em cena pelo locutor, com os quais este se relaciona e que, entretanto, não têm realidade linguística, já que são seres abstratos.

O segundo elemento constitutivo do sentido para Carel e Ducrot (2008) são as atitudes que o locutor toma relativamente aos enunciadores. O locutor pode a) assumir o ponto de vista de um enunciador, atitude esta que tem por objetivo fazer desse ponto de vista o objeto da enunciação; b) concordar com um enunciador, proibindo-se de excluir o ponto de vista de que é origem em momento ulterior do discurso - o que acontece, frequentemente, quando o enunciador é origem de pressupostos; e c) opor-se a um enunciador, descrevendo a enunciação como proibindo-se de, em um momento ulterior do discurso, assumir o ponto de vista de que o enunciador é origem - a atitude de oporse a um enunciador ocorre em enunciados negativos, nos quais o locutor opõe-se ao ponto de vista da afirmação e assume o ponto de vista da negação.

O terceiro elemento constitutivo do sentido é a assimilação que o locutor faz dos enunciadores a seres determinados. O enunciado Para os grevistas, o corte de salários soou como uma afronta apresenta um modo bastante particular de perceber o corte de salários, o modo como os grevistas o entendem e não o modo como o governo, por exemplo, o avalia.

A dupla relação que o locutor mantém com os enunciadores não implica combinações determinadas, ou seja, não é necessário que o locutor, para assumir um ponto de vista de um enunciador, tenha necessariamente de se assimilar a ele. Essa dupla relação, por outro lado, ressalta a importância dos enunciadores e rejeita seu caráter aparentemente supérfluo, visto que "o ponto de vista - imposto no assumir ou mantido na concordância - deve ser definido levando-se em conta a identidade do enunciador, isto é, a assimilação da qual ele foi objeto" (CAREL; DUCROT, 2008, p. 09).

Após esta discussão teórica em torno do conceito de subjetividade e da apresentação de noções necessárias à análise, passemos à descrição e explicação do sentido construído em cada um dos discursos.

\section{Metodologia e análise dos dados}

Os discursos analisados neste artigo têm como título IDH: Brasil sobe no ranking de desenvolvimento da ONU, publicado no portal online da Revista Carta Capital $^{5}$ e IDH do Brasil é inferior à média da América Latina em educação, disponível no portal de notícias $G 1^{6}$. Os discursos não serão reproduzidos na íntegra, entretanto poderão ser acessados nos hiperlinks indicados nas respectivas notas de rodapé. Nossa metodologia consistirá em transcrever e analisar alguns trechos de cada uma das notícias, tendo como objetivo evidenciar, em cada um dos discursos, o posicionamento dos locutores a respeito do tema abordado em seus textos.

\footnotetext{
5 Disponível em: < http://www.cartacapital.com.br/internacional/brasileleva-idh-em-2013-2379.html>. Acesso em: 15 ago. 2015

6 Disponível em: <http://g1.globo.com/mundo/noticia/2014/07/idh-dobrasil-e-inferior-media-da-america-latina-em-educacao.html $>$. Acesso em: 15 ago. 2015
} 
Como afirmamos no início deste trabalho, os discursos que tomamos para estudo foram publicados em julho de 2014 e versam sobre os resultados obtidos pelo Brasil no ranking do IDH divulgado pela ONU. $\mathrm{O}$ que motivou o estudo desses textos foi o fato de, apesar de comentarem os mesmos fatos, cada um deles apresentar um ponto de vista distinto. No primeiro dos discursos, o sentido construído pelo locutor indica que o país obteve um melhor desempenho nos indicadores da qualidade de vida dos seus habitantes e que, portanto, o país está melhorando. Já no segundo discurso, o sentido construído pelo locutor aponta para resultados negativos e, consequentemente, para a piora da qualidade de vida dos brasileiros.

Vejamos a análise de cada um desses discursos, começando pelo título das notícias. Adotaremos o indicador D1 para identificar o discurso 1 e D2 para identificar o discurso 2.

D1 - IDH: Brasil sobe no ranking de desenvolvimento da ONU

D2 - IDH do Brasil é inferior à média da América Latina em educação

O enunciado da manchete do discurso D1 pode ser traduzido pelo encadeamento argumentativo Brasil sobe no ranking de desenvolvimento, portanto o pais está melhorando, cujo aspecto argumentativo que a ele subjaz é subir no ranking DC melhorar. Já o enunciado da manchete do discurso D2 pode ser traduzido pelo encadeamento argumentativo IDH do Brasil é inferior ao da América Latina, portanto o país não está melhorando, ao qual subjaz o aspecto argumentativo ter IDH inferior ao da América Latina DC neg melhorar. Essa análise das duas manchetes aponta para dois pontos.

Em primeiro lugar, a interdependência semântica entre suporte e aporte em cada um dos enunciados é responsável pela construção de sentidos que são opostos: o primeiro orienta o sentido do enunciado para uma melhora, enquanto o outro orienta a construção do sentido para a não melhora, como é evidenciado pelo aporte de cada um dos aspectos.

Em segundo lugar, não se trata exatamente do mesmo bloco semântico, visto que o segmento suporte é distinto em cada um dos aspectos argumentativos. É justamente a diferença entre os suportes que orienta para que o segundo segmento seja de natureza oposta em cada um dos enunciados. O que existe de mais significativo, em termos de diferença entre os suportes, são as palavras sobe, no primeiro enunciado, e inferior, no segundo enunciado. A palavra subir tem uma orientação argumentativa que autoriza ou determina que suas continuações sejam de natureza positiva; já o termo inferior tem uma orientação argumentativa que determina que a ele sejam encadeadas palavras de sentido negativo. Vejamos as argumentações externas de cada uma dessas palavras.

AE subir - subir DC melhorar

AE ser inferior - ser inferior DC ser pior

É importante salientar que as argumentações externas aqui apresentadas são contextuais, ou seja, a orientação argumentativa indica, nesse discurso, uma situação construída pelo locutor como melhor ou como pior. Em outros discursos, há a possibilidade de a orientação argumentativa do termo subir, por exemplo, não permitir que a ele sejam encadeadas continuações de mesma natureza, como no exemplo Os preços subiram nos últimos meses e causaram impacto na inflação. Nesse caso, o verbo subir não permite que a ele seja encadeado o segmento melhorar, visto que não se trata de uma melhora. Esse fato reforça a ideia de que o sentido é construído no uso da língua e de que não está previamente definido em cada palavra da língua:

A palavra, concebida como entidade linguística abstrata, colabora no sentido do enunciado de uma maneira indireta: ela começa por se combinar com as outras palavras para constituir a significação da frase e esta, tendo em vista a situação de discurso, produz o sentido do enunciado. (DUCROT, 1980: 09) (tradução nossa) $)^{7}$.

Acreditamos, portanto, pela análise realizada, que a combinação particular das palavras em cada um dos enunciados, combinação esta que tem como origem um locutor, é responsável pela construção dos sentidos globais de cada uma das manchetes, expressando, cada uma delas, a subjetividade do produtor do discurso.

Vejamos a análise da submanchete de cada uma das notícias.

D1 - Puxado pela educação, País agora é 790 no ranking de desenvolvimento humano da ONU. Em 2012 estava em $85^{\circ}$.

D2 - Média de anos de estudo na região é de 7,9 anos, informa relatório da ONU. No Brasil, média é de 7,2 anos e expectativa de vida é um ano menor.

O enunciado do discurso D1 traduz a melhora apresentada na manchete, sendo essa melhora uma espécie de transformação, expressa pelo encadeamento

\footnotetext{
Le mot, conçu comme entité linguistique abstraite, ne collabore au sens de l'énoncé que d'une façon indirecte : il commence par se combiner aux autres mots pour constituer la signification de la phrase, et est celle-ci qui, vue la situation de discours, produit le sens de l'énoncé. (DUCROT, 1980, p. 09)
} 
subir 6 posições no ranking DC melhorar. Os dêiticos temporais também são responsáveis pela construção do sentido, pois dão a ideia de transformação ao longo do tempo, indicando que se passou de um estado A para um estado B depois de determinada quantidade de tempo transcorrido: estar em 85o posição em T1 PT estar em 79음 posição em $\mathrm{T} 2$. $\mathrm{O}$ aspecto argumentativo transgressivo representa a transformação indicada no enunciado.

Já o enunciado do discurso D2 traduz a não melhora expressa na manchete da respectiva notícia. Nesse caso, não há uma transformação, ao contrário, o sentido construído no título é reforçado, segundo o qual as condições do Brasil não manifestaram melhora, já que estamos em um patamar inferior ao dos nossos países vizinhos. Esse sentido de manutenção de estado pode ser traduzido pelo aspecto argumentativo estar abaixo da média da América Latina DC neg melhorar.

É interessante notar que, em ambos os enunciados, o item que é tomado para comparação é o mesmo: a educação. Enquanto o primeiro enunciado afirma que o Brasil está melhorando, pois os seus índices relativos à educação apresentaram uma evolução, o segundo enunciado afirma exatamente o contrário. É o fato de nosso desempenho na educação (e na expectativa de vida) ser inferior ao dos demais países da América Latina que nos coloca no lugar do não desenvolvimento. Mais uma vez, segundo nossa análise, a subjetividade do locutor marcada pelo ponto de vista referente à realidade que este defende é construído no discurso e não traduz simplesmente uma representação factual dada através da linguagem.

Observemos, agora, o seguinte parágrafo do discurso D1: No Relatório de Desenvolvimento Humano de 2014, que traz o IDH de 2013, o Brasil figura de novo no grupo dos países com desenvolvimento humano 'alto', a segunda entre quatro categorias definidas pelo PNUD [...] De 2012 para 2013, só 38 países melhoraram seu IDH e apenas 18 , ou seja, $10 \%$ do total, conseguiram ganhar posição. O Brasil faz parte dos dois times. Segundo o PNUD, à medida que os países avançam, é mais difícil observar variações no IDH.

A análise desse parágrafo inicia pelo estudo dos aspectos argumentativos subjacentes aos enunciados. São os seguintes: estar novamente no grupo de países com desenvolvimento humano alto DC melhorar; fazer parte do grupo de países que melhoraram seu IDH DC melhorar; fazer parte do grupo de paises que subiram uma posição no IDH DC melhorar. Todos os suportes apresentados pelo locutor têm uma orientação argumentativa que autoriza - e até mesmo impõe - que o aporte seja uma afirmação da melhora da qualidade de vida dos cidadãos brasileiros. É importante observar que, nesses enunciados, o locutor do discurso não afirma explicitamente a melhora, mas constrói seu discurso de tal modo que o leitor é fortemente levado a chegar a essa conclusão. Essa melhora construída no e pelo discurso, segundo nossa análise, está ligada a algumas palavraschave, a que Ducrot (1990d) denomina expressões argumentativas. São as palavras destacadas no texto: só, de novo e apenas. As palavras só e apenas têm um sentido de restrição, o que exclui do grupo um número significativo de determinados seres e, consequentemente, inclui nesse grupo um número pequeno desses mesmo seres. Essa restrição imposta pelas palavras só e apenas é que dá lugar de destaque aos resultados positivos atribuídos ao Brasil. Já a expressão de novo tem um sentido de repetibilidade que pode ser demonstrado pelo aspecto argumentativo ser X em T1 DC ser X em T2, cujo significado aponta para um reforço do sentido de melhora que é construído pelo locutor do discurso D1, uma vez que afirma a permanência do Brasil no grupo dos países que melhoraram a qualidade de vida dos seus habitantes.

Já os trechos dos parágrafos que transcrevemos abaixo, do discurso D2, trazem outro enfoque a respeito dos mesmos dados: O Relatório de Desenvolvimento Humano divulgado nesta quinta-feira (23) pela Organização das Nações Unidas (ONU) informa que o Brasil está abaixo da média da América Latina em educação e expectativa de vida. O estudo das Nações Unidas calcula o Índice de Desenvolvimento Humano dos países com base em indicadores de educação, saúde e renda. O Brasil avançou uma posição no ranking mundial, passando do $80^{\circ}$ lugar em 2012 (IDH de 0,742) para o $79^{\circ} \mathrm{em} 2013$ (IDH 0,744) no ranking do desenvolvimento humano [...].

Os trechos sublinhados apontam para a argumentação construída pelo locutor e para o ponto de vista que defende em seu discurso: de que a qualidade de vida dos brasileiros não está melhorando. Isso é percebido no aspecto argumentativo que subjaz ao primeiro enunciado sublinhado estar abaixo da média da América Latina em educação e expectativa de vida DC não melhorar, bem como no aspecto argumentativo que subjaz ao segundo enunciado sublinhado avançar uma posição no ranking mundial DC neg melhorar. Esse mesmo aspecto argumentativo é apresentado pelo locutor do discurso D1, entretanto, contextualmente, o avanço de uma posição no discurso do locutor da notícia $\mathbf{D} 1$ ganha um sentido de positividade, contrariamente ao que acontece no discurso da notícia D2, no qual ganha um sentido de negatividade. Isso se deve ao fato de os enunciados serem compreendidos em suas relações, já que o modo como aparecem encadeados também é constitutivo do seu sentido - Carel (2011) já havia chamado a atenção para essa evidência, especialmente ao abordar o papel global do texto na determinação da interpretação argumentativa dos enunciados. 
Voltemos ao discurso D1: Os relatórios anuais do IDH têm sempre um enfoque particular. Neste ano, o $P N D U$ decidiu destacar a capacidade de um país de evitar que pessoas que saíram da pobreza voltem à situação anterior. Para a agência, é bom que os países combatam a miséria, mas é preciso ir além e construir politica públicas que respaldem economicamente as populações em casos de grandes crises financeiras ou climáticas, por exemplo. O Bolsa Família é citado como exemplo de política pública a assegurar "resiliência" contra a pobreza. "Constitui um piso de proteção social", afirma Chediek. Nesse trecho do discurso, o locutor dá ênfase à política pública do governo federal chamada Bolsa Família, proposta pelo Brasil para combater a miséria e a pobreza. Essa menção ao Bolsa Família orienta o discurso para um sentido que demonstra que a situação da população brasileira está melhorando, conforme os aspectos argumentativos propor politicas públicas de combate à miséria DC proteger a população e ter políticas públicas de combate à miséria DC melhorar.

Já o locutor do discurso D2 constrói outra argumentação, que aponta para um sentido oposto àquele de D1: Apesar da melhora no ranking, os dados da ONU não revelam avanço significativo em educação e expectativa de vida. [...] A expectativa de vida do brasileiro teve um ligeiro aumento, de 73,7 anos em 2012 para 73,9 anos em 2013. Mas segue abaixo da média latino-americana, de 74,9 anos. O relatório atribui a desaceleração [da elevação do IDH] à crise financeira internacional e sugere a criação de um Fundo Monetário Latino-Americano para completar reservas internacionais que servem de auxílio para países em situação de vulnerabilidade financeira. De acordo com a ONU, 45 milhões de pessoas da América Latina e Caribe correm risco de cair na chamada "pobreza multidimensional", quando há a carência de condições mínimas para a sobrevivência digna, como alimentos e saneamento básico.

No primeiro trecho sublinhado, o locutor parece orientar seu discurso para que o interlocutor seja levado a concluir que o Brasil melhorou. Essa orientação, entretanto, é desfeita quando ao discurso é encadeado um enunciado introduzido pelo operador argumentativo mas, cuja função é pôr em relação conclusões opostas - a expectativa de vida aumentou, mas segue inferior à de nossos vizinhos. Desse modo, há uma reorientação argumentativa no enunciado que aponta para a defesa do ponto de vista que sustenta que os dados não indicam que o país esteja melhorando.

No último trecho da notícia D2, o locutor dá ênfase não mais aos dados da educação como fatores que contribuíram para a estagnação da qualidade de vida, mas chama atenção para o fato de os números relativos à expectativa de vida terem se mantido praticamente inalterados. Esse sentido é materializado nos aspectos argumentativos subjacentes aos enunciados sublinhados. Vejamos abaixo as respectivas análises:

O primeiro dos enunciados tem como argumentação melhora no ranking $P T$ neg avanço, que evoca polifonicamente o aspecto argumentativo que lhe é converso melhora no ranking $D C$ avanço. O locutor assume o aspecto argumentativo transgressivo e opõe-se ao aspecto argumentativo normativo, ambos pertencentes ao mesmo bloco semântico. Já em relação ao segundo enunciado destacado, temos os seguintes aspectos argumentativos que são evocados polifonicamente, ambos conversos um ao outro: melhorar a expectativa de vida PT continuar abaixo da média latina e melhorar a expectativa de vida DC neg continuar abaixo da média latina. Também nesse enunciado o locutor assume o primeiro aspecto argumentativo do par e opõe-se ao segundo. Finalmente, com relação ao terceiro enunciado destacado, o aspecto que lhe é subjacente pode ser expresso nos seguintes termos: haver pessoas em risco de cair na pobreza multidimensional DC neg melhorar, que contraria a argumentação construída pelo locutor do discurso D1, quando este afirma que as políticas públicas de apoio à população dão suporte para que as pessoas não sofram com a miséria e com o desamparo social.

A esses parágrafos analisados seguem-se os parágrafos conclusivos dos discursos, que reafirmam o ponto de vista expresso em cada uma das notícias: o de melhora e o de estagnação, respectivamente pertencentes ao discurso D1 e ao discurso D2. Julgamos que a análise dos trechos transcritos acima é suficiente para esboçarmos algumas reflexões finais que levem em conta a subjetividade e atividade de fala dos sujeitos falantes.

\section{Reflexões sobre a análise}

Ambos os discursos que analisamos pertencem ao mesmo gênero discursivo - notícia - e têm em comum o mesmo tema: a divulgação dos resultados pela ONU no relatório sobre o IDH. Esses discursos, entretanto, apesar de compartilharem dessas características, constroem sentidos totalmente opostos: o primeiro discurso leva o interlocutor a crer que a situação do país está melhorando, enquanto o outro o leva a crer justamente no contrário. Qual é a explicação para o fato de os discursos construírem sentidos tão distintos a partir dos mesmos números que analisam?

Nossa hipótese é de que cada um dos locutores escolheu compor o seu discurso a partir de um recorte específico, ou seja, a partir da sua subjetividade. No texto da Revista Carta Capital - discurso D1 - o sentido construído é o de melhora, já que, para chegar a essa conclusão, o locutor compara os dados obtidos pelo Brasil 
em dois momentos: no ano de 2012 e no ano de 2013 . Os dados do último ranqueamento são mais favoráveis e demonstram que o país avançou uma posição, o que autoriza o locutor a afirmar que houve melhora. Já a notícia do Portal G1 realiza outra comparação: o locutor coteja os dados obtidos pelo Brasil com os dados relativos à América Latina. Apesar de o país ter, de fato, avançado uma posição no ranking, o ponto de vista sustentado pelo locutor do discurso D2 é o de que, em relação ao continente em que estamos situados, a melhora não foi significativa - ou pode ser considerada praticamente inexistente.

Essa escolha feita pelos locutores revela a adoção de um ponto de vista que se materializa no e pelo discurso. Não se trata de realizar, segundo nossa análise, uma descrição dos resultados divulgados pelo órgão internacional, mas sim, de argumentar a partir desses dados com o objetivo de construir determinado sentido ou, ainda, usando as palavras de Ducrot (1990b), de expressar uma atitude diante desses fatos.

O locutor de D1, ao argumentar que o país está melhorando, expressa uma atitude de otimismo, ao mesmo tempo que faz um chamado ao interlocutor, convidando-o a confiar que o país está indo bem. Já o locutor de D2, ao argumentar que o país não está melhorando visto que seus índices ainda permanecem abaixo da média dos países do mesmo continente, expressa uma atitude pessimista, ao mesmo tempo que realiza um chamado ao seu interlocutor, pedindo a ele que tenha desconfiança em relação à situação do nosso país.

Ducrot (1984) afirma que o sentido do discurso pode ser dividido em duas partes: a totalização dos enunciados e a organização no discurso. Por outro lado, o autor afirma que uma das características da linguagem humana é o fato de os segmentos de discurso comentarem a sua própria enunciação. Acreditamos que esses dois aspectos - o linguístico e o enunciativo - expliquem a possibilidade de criarmos sentidos distintos a respeito da realidade, sem ancorar a significação das palavras à realidade extralinguística. A realidade semântica de um discurso é constituída pelas três características apontadas pelo autor: a relação entre enunciados de um discurso, a organização desses enunciados, bem como a imagem da enunciação ou a subjetividade - que neles se encontra marcada.

\section{Referências}

BARROCAL, André. IDH: Brasil sobe no ranking de desenvolvimento da ONU. Carta Capital. Disponível em: $<$ http://www.cartacapital.com.br/internacional/brasil-eleva-idhem-2013-2379.html>. Acesso em: 19 ago. 2015.
BENVENISTE, Émile. Da subjetividade na linguagem. In: BENVENISTE, Émile. Problemas de linguística geral I. Campinas: Pontes Editores, 2005, p. 284-293.

BENVENISTE, Émile. O aparelho formal da enunciação. In: BENVENISTE, Émile. Problemas de Liguística Geral II. Campinas: Pontes Editores, 1989, p. 81-90.

CAREL, Marion. Análise semântica e análise textual. Revista do Programa de Pós-Graduação em Letras da Universidade de Passo Fundo, v. 7, n. 2, p. 184-197, jul.-dez. 2011.

CAREL, Marion; DUCROT, Oswald. Descrição argumentativa e descrição polifônica: o caso da negação. Letras de Hoje, Porto Alegre, v. 43, n. 1, p. 7-18, jan.-mar. 2008.

DUCROT, Oswald. Analyse de textes et linguistique de l'énonciation. In: DUCROT, Oswald et al. Les mots du discours. Paris: Minuit, 1980.

DUCROT, Oswald. Enunciação. Enciclopédia Einaudi. Lisboa: Imprensa Nacional, Casa da Moeda, 1984. p. 368-393.

DUCROT, Oswald. Esboço de uma teoria polifônica da enunciação. In: DUCROT, Oswald. O dizer e o dito. Campinas: Pontes, 1987. p. 161-218.

DUCROT, Oswald. Linguística y verdade. In: DUCROT, Oswald. Polifonía y argumentación. Universidad del Valle, Calli, 1990a. p. 153-171.

DUCROT, Oswald. Primera conferencia. In: DUCROT, Oswald. Polifonía y argumentación. Universidad del Valle, Calli, 1990b. p. 49-64.

DUCROT, Oswald. La polifonía en lingüística. In: DUCROT, Oswald. Polifonía y argumentación. Universidad del Valle, Calli, 1990c. p. 15-29.

DUCROT, Oswald. Segunda conferencia. In: DUCROT, Oswald. Polifonía y argumentación. Universidad del Valle, Calli, 1990d. p. 65-80.

DUCROT, Oswald. Introducción - Conferencia 1. In: CAREL, Marion; DUCROT, Oswald. La semántica argumentativa: una introducción a la teoría de los bloques semánticos. Buenos Aires: Colihue, 2005a,. p. 11-25.

DUCROT, Oswald. Los bloques semánticos y el cuadrado argumentativo - Conferencia 2. In: CAREL, Marion; DUCROT, Oswald. La semántica argumentativa: una introducción a la teoría de los bloques semánticos. Buenos Aires: Colihue, 2005b. p. $29-50$

PASSARINHO, Nathália. IDH do Brasil é inferior à média da América Latina em educação. Portal G1. Disponível em: $<$ http://g1.globo.com/mundo/noticia/2014/07/idh-do-brasil-einferior-media-da-america-latina-em-educacao.html $>$. Acesso em: 19 ago. 2015.

SAUSSURE, Ferdinand de. Curso de Linguística Geral. São Paulo: Cultrix, 2006.

Recebido: 24 de agosto de 2015

Aprovado: 20 de novembro de 2015

Contato: cristianedc@unisc.br 